\title{
Characterization of the Hippocampal Neuroimmune Response to Binge-Like Ethanol Consumption in the Drinking in the Dark Model
}

\author{
Isabella R. Grifasia Scot E. Mclntosh ${ }^{a}$ Rhiannon D. Thomas ${ }^{b}$ Donald T. Lysle ${ }^{b, c}$ \\ Todd E. Thiele ${ }^{b, c}$ S. Alex Marshalla, \\ ${ }^{a}$ Department of Basic Pharmaceutical Sciences, Fred P. Wilson School of Pharmacy, High Point University, High \\ Point, NC, USA; ${ }^{b}$ Department of Psychology and Neuroscience, The University of North Carolina, Chapel Hill, NC, \\ USA; ${ }^{C}$ Bowles Center for Alcohol Studies, The University of North Carolina, Chapel Hill, NC, USA
}

\section{Keywords}

Alcohol abuse $\cdot$ Cytokine $\cdot$ Astrocyte activation .

Neuroimmune $\cdot$ Hippocampus $\cdot$ Binge drinking

\begin{abstract}
Objectives: Alcohol dependence leads to dysregulation of the neuroimmune system, but the effects of excessive alcohol consumption on key players of the neuroimmune response after episodic binge drinking in nondependence has not been readily assessed. These studies seek to determine how the neuroimmune system within the hippocampus responds to binge-like consumption prior to dependence or evidence of brain damage. Methods: C57BL/6J mice underwent the drinking in the dark (DID) paradigm to recapitulate binge consumption. Immunohistochemical techniques were employed to determine the effects of ethanol on cytokine and astrocyte responses within the hippocampus. Astrocyte activation was also assessed using qRT-PCR. Results: Our results indicated that binge-like ethanol consumption resulted in a 3.6-fold increase in the proinflammatory cytokine interleukin (IL)-1 $\beta$ immunoreactivity in various regions of the hippocampus. The opposite effect was seen in the anti-inflammatory cytokine IL-10. Binge-like consumption re-
\end{abstract}

\section{KARGER}

(c) 2019 S. Karger AG, Basel

E-Mail karger@karger.com

www.karger.com/nim sulted in a $67 \%$ decrease in IL-10 immunoreactivity but had no effect on IL-4 or IL-6 compared with the water-drinking control group. Moreover, astrocyte activation occurred following ethanol exposure as GFAP immunoreactivity was increased over $120 \%$ in mice that experienced 3 cycles of ethanol binges. PCR analyses indicated that the mRNA increased by almost 4-fold after one cycle of DID, but this effect did not persist in abstinence. Conclusions: Altogether, these findings suggest that binge-like ethanol drinking prior to dependence causes dysregulation to the neuroimmune system. This altered neuroimmune state may have an impact on behavior but could also result in a heightened neuroimmune response that is exacerbated from further ethanol exposure or other immune-modulating events.

(c) 2019 S. Karger AG, Basel

\section{Introduction}

Alcohol use disorders (AUDs) are a prevalent epidemiological issue both in the USA and abroad $[1,2]$. Problems associated with alcohol misuse affect various societal constructs, including the economy, health care systems, and interpersonal relationships $[3,4]$. The majority of these 
problems occur as a result of binge drinking, making it particularly problematic [5]. Binge drinking is defined as consuming enough alcohol to reach a blood ethanol concentration (BEC) of $80 \mathrm{mg} / \mathrm{dL}$ in a short period of time [6]. It is well established that repetitive binge drinking can induce neuroplastic events that alter the physiologic responses to alcohol and are thought to be one of the underlying mechanisms leading to the development of an AUD [7-10]. Although alcohol abuse can elicit maladaptations in various biologic systems, this study focuses on alcohol-induced neuroimmune responses as the neuroimmune system has the capacity to contribute to both alcohol-induced neurodegeneration and alcohol's pharmacodynamic properties [11, 12]. For example, increases in the proinflammatory cytokine tumor necrosis factoralpha after repeated ethanol consumption has been proposed as an underlying factor in alcohol-induced brain damage in the peri-entorhinal cortex $[13,14]$. Moreover, alcohol's effects on the proinflammatory cytokine interleukin-1 $($ IL-1 $\beta$ ) in the amygdala alters neurotransmission and has behavioral implications [15-17]. Elucidating the impact of alcohol on the neuroimmune system during various periods of alcohol abuse is critical to determining how it contributes to the cycle of alcohol misuse and the development of AUDs.

Preclinical studies examining alcohol-induced neuroimmune responses have predominantly focused on models of alcohol dependence. Alcohol-dependence studies suggest that the neuroimmune response can exacerbate neuronal cell death through both hyper- and hyporeactivity [13, 18-21]. Although alcohol dependence and binge-like consumption share many neurobiological underpinnings, determining the neurochemical maladaptations that occur specifically after binge drinking in nondependent individuals merits separate attention as the effects of dependence and binge drinking can be distinct [22]. Koob [9] has published multiple reports on the differences between the neurobiological contributions of positive reinforcement during initial alcohol abuse (e.g., binge drinking) and the negative reinforcement associated with withdrawal and physical dependence from alcoholism. In fact, most individuals who binge drink do so sporadically and will never be diagnosed with or reach the criteria for alcohol dependence [23, 24]. When one also considers the "quasi" social acceptability of bingeing [25, 26], it becomes clear why understanding the neurobiological consequences of binge drinking in nondependent states is crucial. Discerning the neurologic effects of alcohol in nondependent individuals is especially relevant to the neuroimmune system because neuroimmune re- sponses can be primed by an initial insult leading to an exacerbated response in the presence of secondary immunomodulators [27-29]. These secondary immunomodulators could be more ethanol use in dependence or an infectious pathogen. For example, in a model of alcohol dependence, the Crews lab was able to show that ethanol experience exacerbates the effects of a peripheral infection on the neuroimmune system and neurodegeneration $[29,30]$. Because binge drinking often occurs as multiple events and overlaps with other pathological problems, it is necessary to elucidate the neuroimmune responses across the AUD spectrum, including more acute binge exposures [20]. This study specifically focuses on the contribution of binge drinking to neuroimmune responses independent of alcohol dependence to highlight differences between ethanol's effects on the neuronal environment during alcohol abuse compared with dependence.

To distinguish between the neuroimmune effects specifically associated with binge drinking and those in dependence, these studies utilize the drinking in the dark (DID) paradigm. The DID model is uniquely suited for an examination of the neuroimmune profile as a result of binge-like consumption prior to alcohol dependence [31, 32]. This study extends our previous findings on alcohol's effects on amygdala cytokines by determining the impact of alcohol on cytokines and astrocytes in the hippocampus $[15,33]$. The hippocampus has been chosen as the region of interest because both clinical and preclinical studies have repeatedly shown it to be susceptible to the detrimental effects of excessive alcohol consumption [34-37]. This study examines the neuroimmune response to binge-like alcohol consumption using immunohistochemical (IHC) analysis of the anti-inflammatory cytokines IL-10 and IL-4, and the pro-inflammatory cytokines IL- $1 \beta$ and IL- 6 , in the dentate gyrus (DG), cornu ammonis 1 (CA1), and cornu ammonis $2 / 3$ (CA2/3) hippocampal subfields. Astrocyte activation was assessed using both IHC procedures and qRT-PCR.

\section{Materials and Methods}

\section{Animals}

Male C57BL/6J mice (6-8 weeks; $n=121$ ) from Jackson Laboratories (Bar Harbor, ME, USA) were individually housed in a reversed 12:12-h light:dark cycle vivarium maintained at $22^{\circ} \mathrm{C}$. During the experiments, animals had ad libitum access to water and chow unless otherwise indicated. The mice used to assess cytokines were given a Teklad Diet ${ }^{\circledR}$ 2920X (Harlan Laboratories Inc., Indianapolis, IN, USA), but the mice used to assess astrocyte activation received Prolab ${ }^{\circledR}$ RMH 3000 (Purina LabDiet ${ }^{\circledR}$, St. Louis, MO, USA) due to a change in the standard diet provided by our
Grifasi/McIntosh/Thomas/Lysle/Thiele/ Marshall 
Table 1. DID binge data for immunohistochemistry

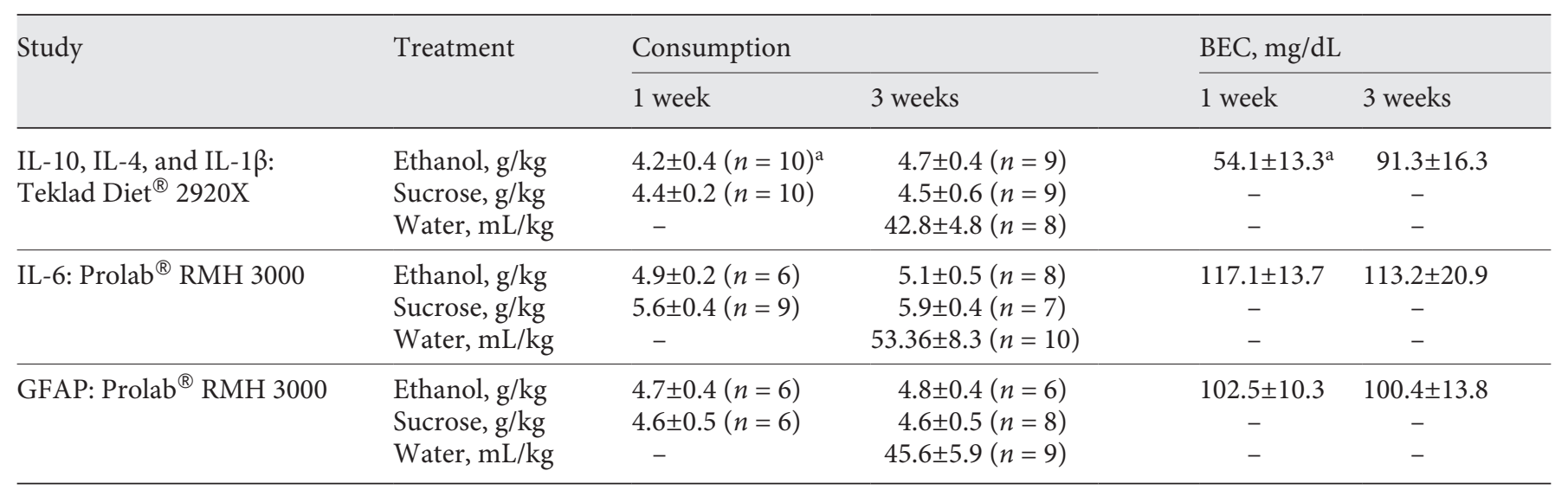

BEC, blood ethanol concentration.

a The Teklad diet significantly reduced ethanol consumption and BECs during week 1.

university [38]. All animals were given at least a week to acclimatize to the environment before experimentation. The procedures used in this study were all approved by both High Point University and the University of North Carolina's Institutional Animal Care and Use Committees following the Guidelines for the Care and Use of Laboratory Animals.

\section{DID Procedures}

Nondependent binge drinking was modeled using a 4-day DID paradigm as previously described $[31,39]$. Briefly, home cage water bottles were removed $3 \mathrm{~h}$ into the dark cycle, and the mice received access to a single bottle of $20 \%(\mathrm{v} / \mathrm{v})$ ethanol solution or a control solution of either $3 \%(\mathrm{w} / \mathrm{v})$ sucrose or tap water. For the first 3 days of each cycle mice had $2 \mathrm{~h}$ of access, but on the fourth day consumption $(\mathrm{g} / \mathrm{kg})$ was measured over $4 \mathrm{~h}$. The mice used in IHC experiments went through the DID procedure for 1 or 3 cycles with each 4 -day DID cycle separated by 3 days [32]. Tail blood samples (approx. $60 \mu \mathrm{L}$ ) were taken from tail nicks immediately following the final DID procedure to determine BEC. Control animals were also subjected to the tail nick procedure to mitigate the effects of the stress associated with the procedure on neuroimmune measurements. Serum was obtained through centrifugation and run in duplicates using the AM1 Alcohol Analyzer (Analox, London, UK) for BEC determination $(\mathrm{mg} / \mathrm{dL})$. The mice were euthanized by transcardial perfusion following the final DID, similar to the procedure of previous studies $[15,33]$. Briefly, an overdose of a mixture of ketamine and xylazine $(66.67$ and $6.67 \mathrm{mg} / \mathrm{mL}$, respectively; $0.9 \%$ saline) was administered before perfusion with $0.1 \mathrm{M}$ phosphate-buffered saline (PBS; $\mathrm{pH}=7.4$ ) and $4 \%$ paraformaldehyde in PBS ( $\mathrm{pH}=7.4)$. Brains post-fixed in paraformaldehyde were sliced using a vibratome (Leica VT1000S; Wetzlar, Germany) to obtain 40- $\mu \mathrm{m}$ coronal sections.

For PCR studies, however, the mice were subjected to a single cycle of DID and euthanized immediately, 1 day, or 10 days after ethanol consumption. The brains were removed following rapid decapitation and the hippocampus was dissected out and flash frozen on dry ice. To avoid changes in mRNA associated with re-
Table 2. Methods for antigen detection

\begin{tabular}{lll}
\hline Antibody & $\begin{array}{l}\text { Concen- } \\
\text { tration }\end{array}$ & $\begin{array}{l}\text { Incubation } \\
\text { time, } \mathrm{h}\end{array}$ \\
\hline Rb anti-IL-1 $\beta$ (R\&D Systems) & $1: 1,000$ & 48 \\
Rb anti-IL-10 (R\&D Systems) & $1: 1,000$ & 48 \\
Gt anti-IL-4 (Lifespan BioSciences) & $1: 2,000$ & 72 \\
Rb anti-IL-6 (Rockland) & $1: 500$ & 48 \\
Rb anti-GFAP (Sigma Aldrich) & $1: 500$ & 72 \\
\hline
\end{tabular}

straint stress, blood was only taken for animals euthanized immediately by collecting trunk blood [40].

\section{IHC and Immunoreactivity Quantification}

Three cohorts of animals were used for IHC procedures targeting the cytokines IL-1 $\beta$, IL-4, IL-6, and IL-10 as well as glial fibrillary acidic protein (GFAP; see Table 1 for group details). GFAP was used as a marker of morphological change and activation in astrocytes. IHC techniques were similar to previous studies [15, 33, 41]. Briefly, cryoprotectant was removed in a series of rinses in $0.1 \mathrm{M}$ of PBS before endogenous peroxidases were quenched with $0.6 \% \mathrm{H}_{2} \mathrm{O}_{2}$. Sections used for IL-10 IHC analysis then underwent an additional step of antigen retrieval in citrate buffer at $65^{\circ} \mathrm{C}$ for $1 \mathrm{~h}$. After serial PBS washes, all nonspecific binding was blocked (PBS/0.1\% triton-X/3\% rabbit or goat serum; Vector Laboratories, Burlingame, CA, USA). Sections were then incubated in primary antibody (see Table 2 for additional details). After the primary antibody was removed by serial washes in block, the sections were incubated in the primary appropriate biotinylated secondary antibody $(1: 2,000)$ for $1 \mathrm{~h}$, followed by signal amplification with an avidin-biotin-peroxidase complex (ABC elite kit, Vector Labs) for $1 \mathrm{~h}$. Finally, the chromagen, 3,3'-diaminobenzidine tetrahydrochloride (Polysciences; Warrington, PA, USA) was used for detec- 
Table 3. DID binge data for PCR

\begin{tabular}{llcc}
\hline Study & Treatment & $\begin{array}{l}\text { Consumption, } \\
\mathrm{g} / \mathrm{kg}\end{array}$ & $\begin{array}{l}\mathrm{BEC}, \\
\mathrm{mg} / \mathrm{dL}\end{array}$ \\
\hline PCR: & Ethanol + 0 days $(n=10)$ & $5.1 \pm 0.3$ & $102.0 \pm 12.5$ \\
Prolab $^{\circledR}$ & Ethanol + 1 day $(n=10)$ & $4.8 \pm 0.4$ & - \\
RMH 3000 & Ethanol + 10 days $(n=12)$ & $5.0 \pm 0.4$ & - \\
& Water $(n=8)$ & $37.3 \pm 3.1$ & - \\
\hline
\end{tabular}

BEC, blood ethanol concentration.

tion of the antigen of interest. Mounted sections were coverslipped with SHUR/Mount ${ }^{\mathrm{TM}}$ (Triangle Biomedical Sciences, Durham, NC, USA).

Either a Zeiss Axio Zoom V16 macroscope (Zeiss, Jena, Germany) or Nikon Eclipse 80i with an Olympus DP73 digital camera was used to image the sections at $100 \times$ magnification. For all images, experimental bias was avoided by coding the slide images prior to quantification. The subregions of the hippocampus (DG, $\mathrm{CA} 1$, and CA2/3) were individually traced on sections between Bregma -1.06 and $-2.54 \mathrm{~mm}$ [42]. Approximately 6-8 sections were analyzed per animal. Animals that did not have at least 6 analyzable sections within the area of interest were excluded from the study. Immunoreactivity was measured with Zen Pro 2012 (Zeiss) or CellSens (Olympus) using experimenter-determined optical density thresholds. Immunoreactivity is expressed as the percentage area (immunoreactive positive area/total area of region of interest).

\section{$q R T-P C R$}

RNA was extracted in a fourth cohort of animals ( $n=40$; see Table 3 for details) from hippocampal tissue homogenized in 200 $\mu \mathrm{L}$ of Trizol ${ }^{\circledR}$ (Invitrogen Corporation, Carlsbad, CA, USA) using a PowerGen tissue homogenizer, identical to previous studies [43, 44]. The total RNA was quantified using a Qubit ${ }^{\circledR} 3.0$ Fluorometer, and $1 \mu \mathrm{g}$ of RNA was reversed transcribed to cDNA. Standard Taq$\mathrm{Man}^{\circledR}$ assays were purchased from ThermoFisher Scientific for the measurement of GFAP (Mm01253033_m1) and an endogenous control PPIA (Mm02342430_g1). Each sample was run in triplicate using the Quant Studio 6 Flex (Invitrogen). Measurements were normalized to the water groups and are expressed as the fold change, similar to previous reports $[15,45]$.

\section{Statistical Analysis}

Prism version 7.02 (GraphPad Software Inc., La Jolla, CA, USA) was used to analyze and graph all data reported herein. ANOVAs were used to assess ethanol consumption, immunoreactivity, and fold change of mRNA. Post hoc tests were only utilized if a main effect of treatment was observed. Dunnett's post hoc tests were used for all post-analyses with the water group serving as the control group except BECs, where Bonferroni tests were used because there was no true control group. All data are reported as the mean \pm standard error of the mean and considered significant with two-tailed $p<0.05$.

\section{Results}

Ethanol Consumption and BECs Impacted by Diet

A two-way ANOVA (cohort $\times$ number of cycles) of ethanol consumption $(\mu=4.98 \pm 0.31)$ indicated a main effect of cohort $\left(F_{(2,40)}=3.31, p=0.047\right)$ but not number of cycles $\left(F_{(1,40)}=0.29, p=0.59\right)$ or an interaction $\left(F_{(2,40)}=0.52, p=0.59\right.$; Table 1$)$. Importantly, the average BEC $(\mu=98.1 \pm 11.9 \mathrm{mg} / \mathrm{dL})$ was above the threshold of binge-like consumption. A two-way ANOVA indicated that the BECs were significantly different between the groups associated with a main effect of cohort group $\left(F_{(2,40)}=4.36, p=0.02\right)$. However, no interaction $\left(F_{(2,40)}=\right.$ $1.15, p=0.32)$ or effect of the number of cycles $\left(F_{(1,40)}=\right.$ $0.64, p=0.43$ ) were found for the BECs. Post hoc analyses indicated that cohort 1 animals receiving the Teklad diet had lower consumption and BECs compared with the other animal cohorts during the first week of DID exposure, but this effect did not continue after 3 weeks of exposure. This finding reinforces previous studies that suggest changes in standard protocols like diet can impact behavioral outcomes [38, 46].

Due to differences in the number of DID cycle exposures, animals used in the PCR study could not be included in a two-way ANOVA and were analyzed separately (Table 3). The average BEC $(\mu=102.0 \pm 12.5 \mathrm{mg} / \mathrm{dL})$ was also above the threshold of binge-like consumption in this cohort. No differences were observed in consumption among the groups according to a one-way ANOVA $\left(F_{(2,29)}=0.31, p=0.73\right)$.

\section{Binge-Like Ethanol Consumption Promotes a \\ Proinflammatory Cytokine Environment}

Photomicrographs indicate that there is basal expression of IL- $1 \beta$, IL- 6 , IL- 4 , and IL-10 in the hippocampus, as shown in the control group for each cytokine assessed. One-way ANOVAs revealed that binge-like ethanol drinking resulted in increased IL-1 $\beta$ immunoreactivity

Fig. 1. Representative photomicrographs at $\times 100$ magnification of IL- $1 \beta$ within the hippocampus of mice exposed to water (a), 3 sucrose DID cycles (b), 1 ethanol DID cycle (c), and 3 ethanol DID cycles (d). Inset A cell expressing IL- $1 \beta$ at $\times 400$ magnification. Our analyses indicated that 3 cycles of ethanol (EtOH) exposure resulted in an increase in IL- $1 \beta$ immunoreactivity within the DG (h) and CA1 (i), but not the CA2/3 (j). Moreover, no statistically significant differences were observed between the water and sucrose (Suc) drinking groups in any subregion of the hippocampus $(\mathbf{e}-\mathbf{g})$. c Scale bar, $10 \mu \mathrm{m}$. Each photomicrograph has traces outlining the hippocampal fissure. All data are presented as the mean \pm SEM. $* p<0.05$ compared to the water group.

(For figure see next page.) 


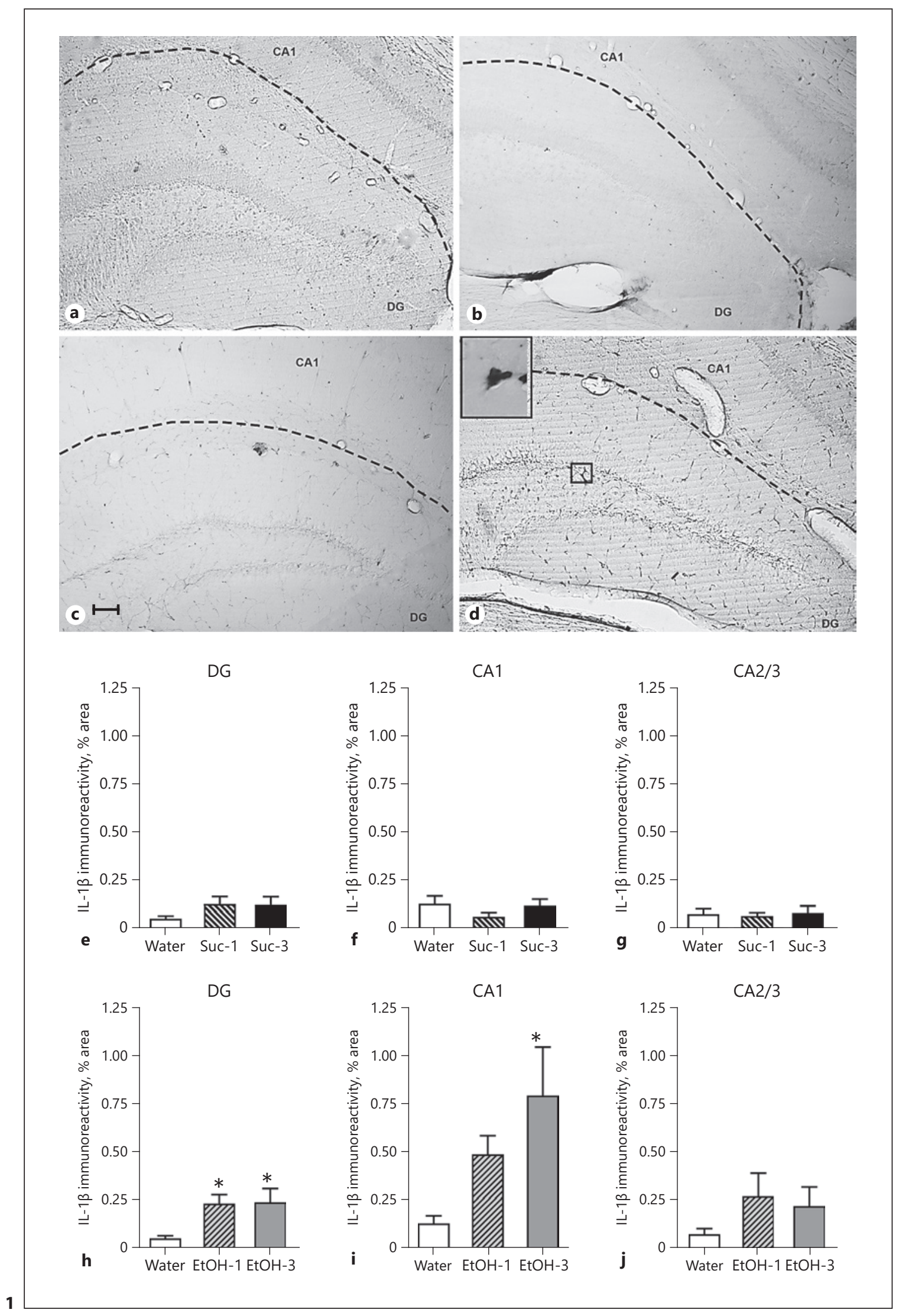



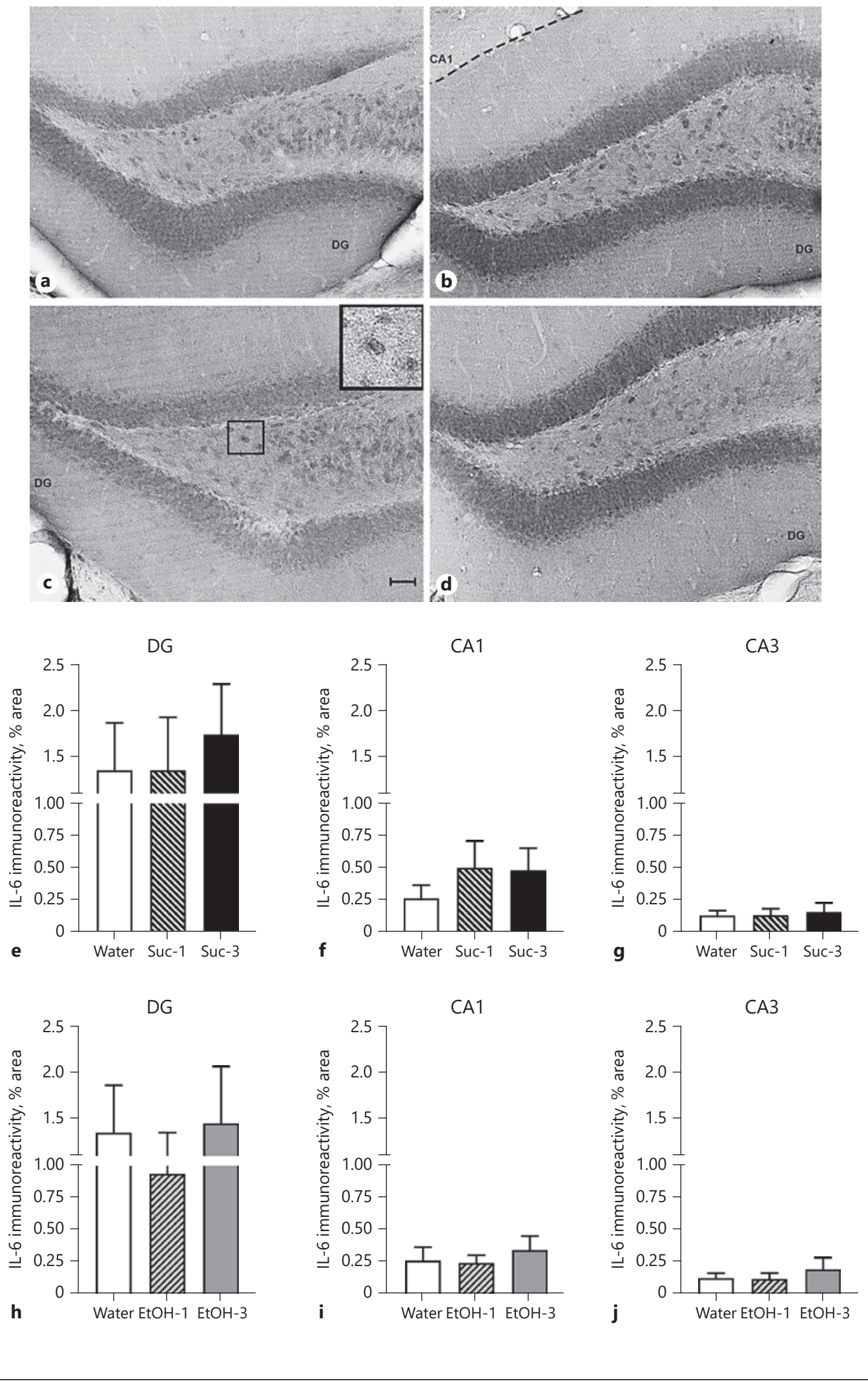

2 
compared with the water-drinking control group in the $\operatorname{DG}\left(F_{(2,24)}=4.04, p=0.03\right)$ and CA1 $\left(F_{(2,24)}=4.05, p=\right.$ $0.03)$, but not the CA2/3 $\left(F_{(2,24)}=0.09, p=0.91\right)$ subregions of the hippocampus (Fig. 1). Post hoc Dunnett's multiple comparison tests indicated a significant increase of IL-1 $\beta$ immunoreactivity in mice that experienced 3 cycles of DID in both the DG and the CA1 compared with water-drinking control mice $(p<0.05)$. However, the DG appeared to be more susceptible to ethanol as even one cycle of the DID paradigm resulted in significant upregulation of IL- $1 \beta$. Sucrose consumption did not alter IL- $1 \beta$ immunoreactivity in any region assessed (DG: $\left[F_{(2,24)}=1.34, p=0.28\right]$; CA1: $\left[F_{(2,24)}=1.45, p=0.25\right]$; CA2/3: $\left.\left[F_{(2,24)}=0.10, p=0.91\right]\right)$. Moreover, no changes in IL-6 immunoreactivity were associated with either ethanol (DG: $\left[F_{(2,20)}=0.21, p=0.81\right]$; CA1: $\left[F_{(2,20)}=0.24, p=0.78\right] ; \mathrm{CA} 2 / 3:\left[F_{(2,20)}=0.48\right.$, $p=0.63]$ ) or sucrose (DG: $\left[F_{(2,23)}=0.16, p=0.85\right]$; CA1: $\left.\left[F_{(2,23)}=0.75, p=0.48\right] ; \mathrm{CA} 2 / 3:\left[F_{(2,23)}=0.07, p=0.93\right]\right)$ consumption in the hippocampus (Fig. 2).

IL-10 immunoreactivity was only depressed in the CA1 $\left(F_{(2,24)}=4.13, p=0.03\right)$ of animals that experienced binge-like ethanol with no significant effects in the DG $\left(F_{(2,24)}=0.02, p=0.98\right)$ or CA2/3 $\left(F_{(2,24)}=0.07, p=0.93\right)$ subregions compared to the water group. Post hoc Dunnett's multiple comparison tests indicated a significant decrease in IL-10 immunoreactivity in the CA1 of mice that experienced 3 cycles of DID, but not mice that experienced 1 cycle, compared to the water-drinking control mice $(p<0.05)$. Importantly, no difference was indicated by one-way ANOVAs between animals drinking water versus sucrose in any of the hippocampal subregions $\left(\mathrm{DG}:\left[F_{(2,24)}=0.55, p=0.58\right]\right.$; CA1: $\left[F_{(2,24)}=0.03, p=\right.$ 0.97]; $\left.\mathrm{CA} 2 / 3:\left[F_{(2,24)}=0.27, p=0.76\right]\right)$, suggesting that decreased IL-10 concentrations were specific to ethanol consumption and no other rewarding solutions (Fig. 3). Moreover, no changes in IL-4 immunoreactivity were associated with either ethanol (DG: $\left[F_{(2,24)}=0.03, p=0.97\right]$; CA1: $\left[F_{(2,24)}=2.43, p=0.11\right]$; CA2/3: $\left[F_{(2,24)}=0.79, p=\right.$ $0.47])$ or sucrose (DG: $\left[F_{(2,24)}=0.03, p=0.97\right]$; CA1: $\left.\left[F_{(2,24)}=1.61, p=0.22\right] ; \mathrm{CA} 2 / 3:\left[F_{(2,24)}=1.17, p=0.33\right]\right)$ consumption in the hippocampus (Fig. 4 ).

Fig. 2. Representative photomicrographs of IL-6 within the hippocampus of mice exposed to water (a), 3 sucrose DID cycles (b), 1 ethanol DID cycle (c), and 3 ethanol DID cycles (d). Inset A cell expressing IL-6 at $\times 400$ magnification. Analyses indicated that neither ethanol (EtOH; $\mathbf{h}-\mathbf{j}$ ) nor sucrose (Suc; e-g) had any effect on IL-6 expression within the regions of the hippocampus compared with the water control. c Scale bar, $10 \mu \mathrm{m}$. Each photomicrograph has traces outlining the hippocampal fissure.

\section{Astrocyte Activation Associated with Repeated} Binge-Like Consumption

Astrocytes were assessed using GFAP immunoreactivity. Although GFAP is a marker for all astrocytes, upregulation of GFAP immunoreactivity is a common tool to examine astrocyte activation $[41,47]$. One-way ANOVAs indicated that ethanol significantly increased GFAP immunoreactivity in the $\mathrm{DG}\left(F_{(2,18)}=15.77, p=0.0001\right)$ and CA1 $\left(F_{(2,18)}=6.79, p=0.006\right)$ but not the CA2/3 region $\left(F_{(2,18)}=2.99, p=0.08\right)$. Post hoc Dunnett's multiple comparison tests indicated a significant increase in GFAP immunoreactivity in the DG and CA1 of mice that experienced 3 cycles of DID but not 1 cycle compared to the water-drinking control mice ( $p<0.05$; Fig. 5$)$. No effect of sucrose consumption was seen in any subregions of the hippocampus $\left(\mathrm{DG}\left[F_{(2,20)}=1.68, p=0.21\right]\right.$; $\mathrm{CA} 1\left[F_{(2,20)}=\right.$ $\left.2.08, p=0.15] ; \mathrm{CA} 2 / 3\left[F_{(2,20)}=2.19, p=0.14\right]\right)$.

\section{Increases in GFAP mRNA during Intoxication from Binge-Like Consumption}

To determine if changes in GFAP persist during abstinence, mRNA was measured immediately, 1 day, and 10 days after ethanol consumption. A one-way ANOVA indicated a significant impact of treatment $\left(F_{(3,36)}=4.67\right.$, $p=0.007)$ on GFAP mRNA expression. Dunnett's post hoc multiple comparison test revealed that immediately after ethanol consumption there was a significant increase in GFAP mRNA compared with the water controls. However, no changes were observed in either of the abstinent groups ( 1 or 10 days) compared with the wateronly group (Fig. 6).

Fig. 3. Representative photomicrographs of IL-10 within the hippocampus of mice exposed to water (a), 3 sucrose DID cycles (b), 1 ethanol DID cycle (c), and 3 ethanol DID cycles (d). Inset A cluster of cells expressing IL-10 at $\times 400$ magnification. Analyses indicated that 3 cycles of ethanol (EtOH) reduced IL-10 within the CA1 (i), but this effect of ethanol was not present in either the DG (h) or the CA2/3 (j). Moreover, no statically significant differences were observed between the water and sucrose (Suc) drinking groups in any subregion of the hippocampus $(\mathbf{e}-\mathbf{g})$. c Scale bar, 10 $\mu \mathrm{m}$. Each photomicrograph has traces outlining the hippocampal fissure. All data are presented as the mean \pm SEM. ${ }^{*} p<0.05 \mathrm{com}-$ pared to the water group.

Fig. 4. Representative photomicrographs of IL-4 within the hippocampus of mice exposed to water (a), 3 sucrose DID cycles (b), 1 ethanol DID cycle (c), and 3 ethanol DID cycles (d). Inset A cell expressing IL-4 at $\times 400$ magnification. Analyses indicated that neither ethanol (EtOH; $\mathbf{h}-\mathbf{j}$ ) nor sucrose (Suc; e-g) had any effect on IL-4 expression within the regions of the hippocampus. c Scale bar, $10 \mu \mathrm{m}$. Each photomicrograph has traces outlining the hippocampal fissure.

(For figures see next pages.)

Neuroimmunomodulation 2019;26:19-32

Nondependent Binge-Induced

Neuroimmune Responses in the

Hippocampus

DOI: $10.1159 / 000495210$ 


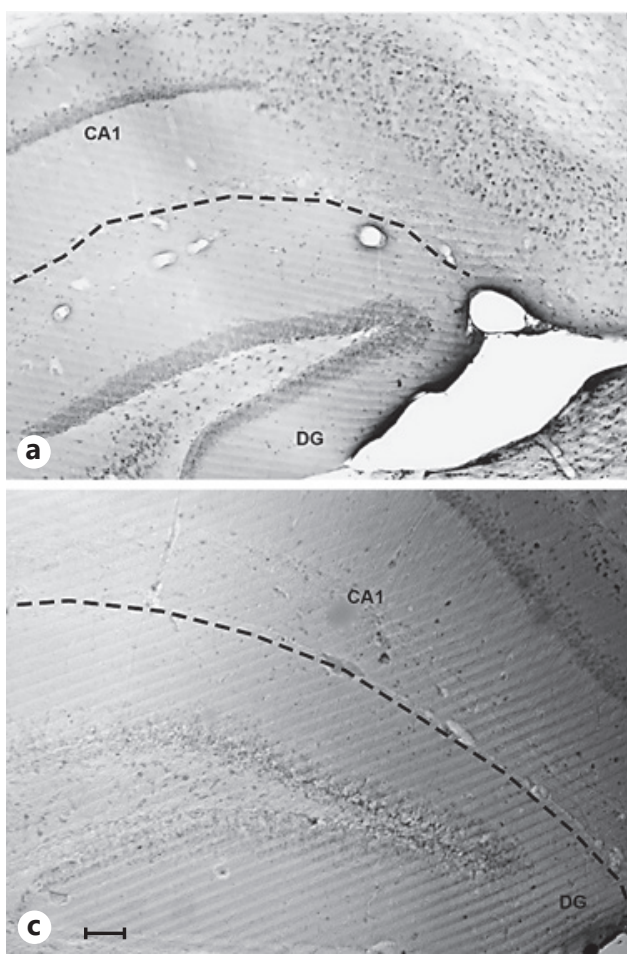

DG
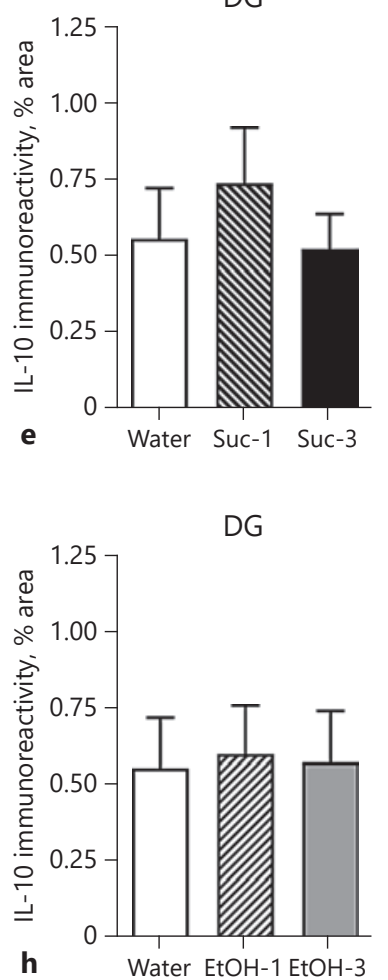

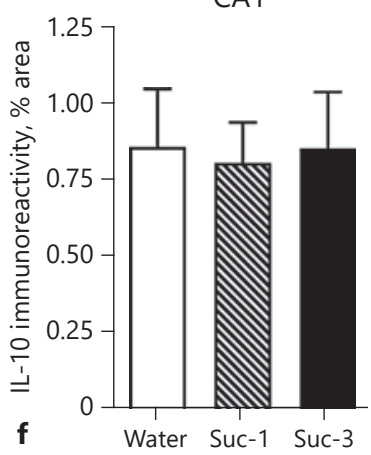

CA1

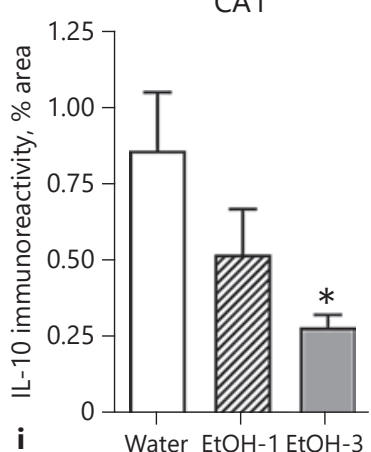

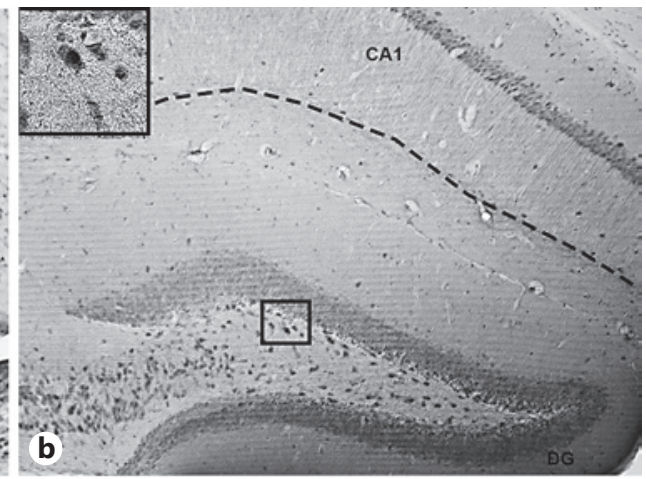

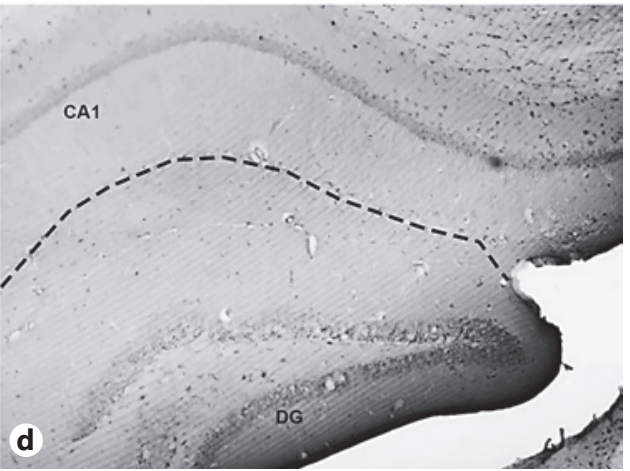

CA1

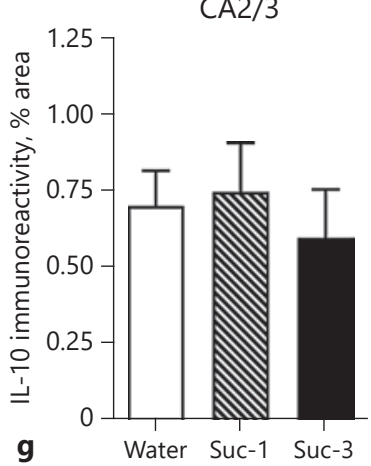

$\mathrm{CA} 2 / 3$

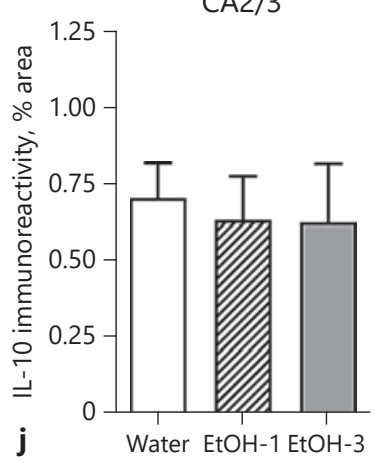




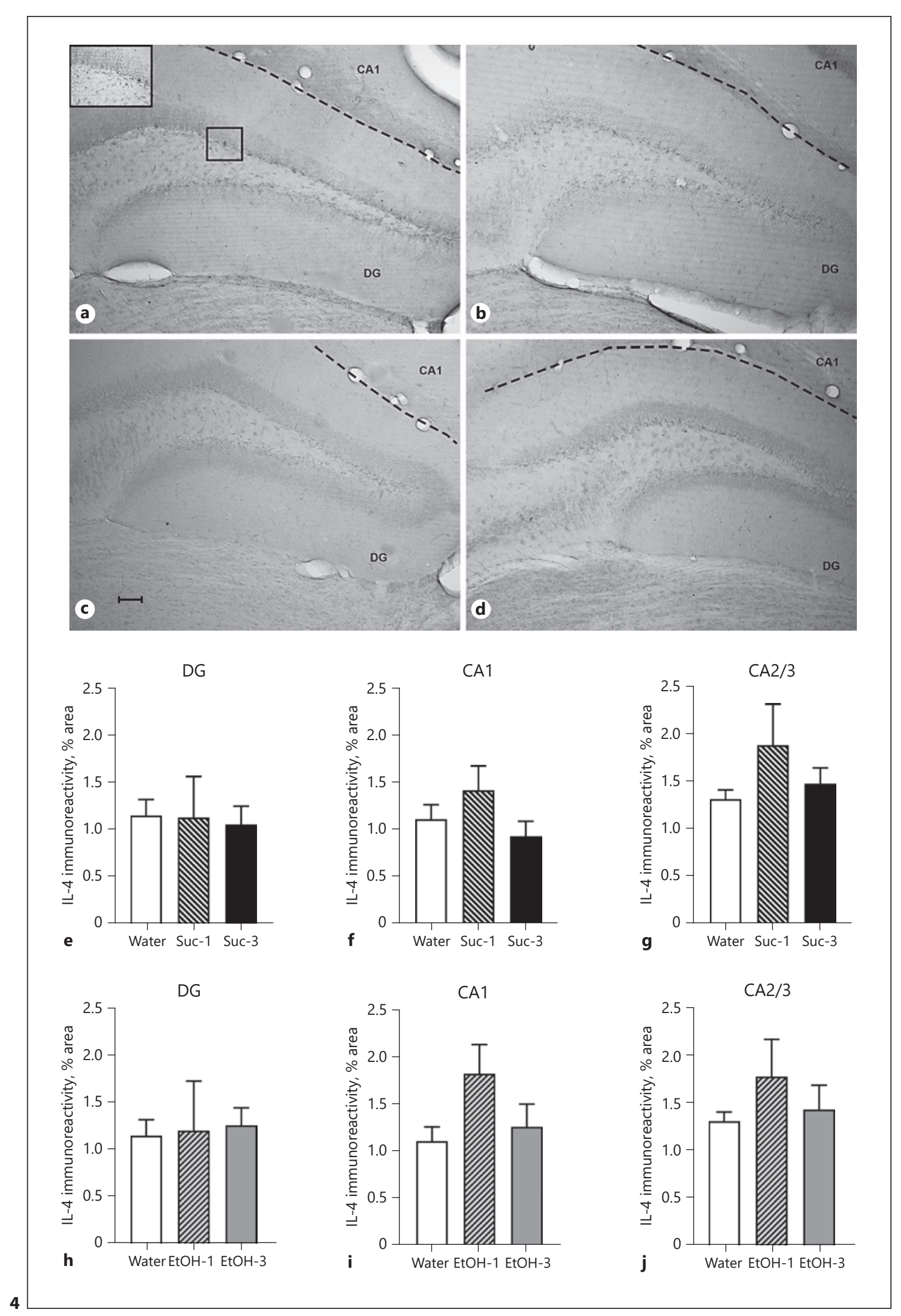




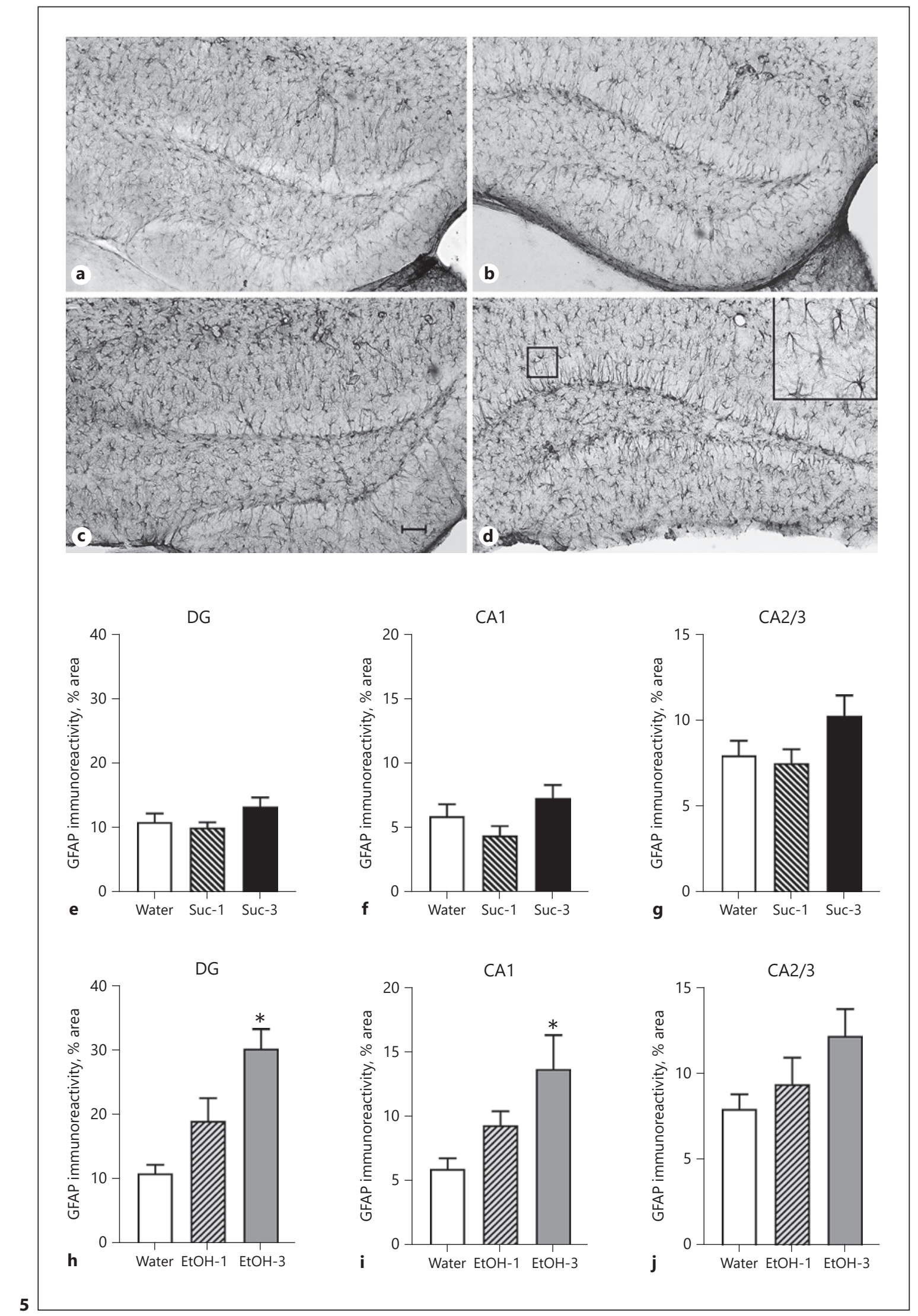

(For legend see next page.) 


\section{Discussion}

The reciprocal and reinforcing relationship between alcohol misuse and the various actors of the neuroimmune response remains of distinct interest in developing therapies to curb alcohol abuse. This report identified key neuroimmune responses in the hippocampus following binge-like consumption in a nondependent model. More specifically, these data indicate that mice with DID ethanol experience had: (a) an induction of IL-1 $\beta$, (b) a decrease in IL-10, and (c) an initiation of astrocyte activation in the hippocampus. Importantly, these signs of a neuroimmune response were seen prior to evidence of either dependence-like phenotypes or evidence of neurodegeneration $[15,31,48]$.

The alcohol-induced cytokine milieu results described herein align with our previous studies examining the neuroimmune response to binge-like consumption in the DID model. Our previous reports indicate that there was a similar depression of IL-10 and an increase in IL- $1 \beta$ in the basolateral amygdala $[15,33]$. However, this is the first report to specifically examine these cytokines within the hippocampus in this AUD model. It is important to denote that the effect of alcohol on cytokines were not universal, as no changes were observed in either IL-4 or IL-6 immunoreactivity, suggesting that the ethanol effects are somewhat selective. Moreover, regional differences were observed within the hippocampus depending on the cytokine of interest. These results are similar to those seen in models of dependence as well as fetal alcohol spectrum disorders, which have shown that the cytokines in the hippocampus are changed following chronic consumption, or in models with BECs well over $300 \mathrm{mg} / \mathrm{dL}$ $[13,19,37,49,50]$. However, the altered cytokine milieu observed herein reflects maladaptations that occur just above the legal limit of $80 \mathrm{mg} / \mathrm{dL}$. Considering IL- 6 and IL-4 were not impacted during this nondependent binge-

Fig. 5. Representative photomicrographs of astrocytes within the dentate gyrus of mice exposed to water (a), 3 sucrose DID cycles (b), 1 ethanol DID cycle (c), and 3 ethanol DID cycles (d) indicate an effect of ethanol on GFAP immunoreactivity. Inset GFAP+ cells at $\times 400$ magnification. Our analyses showed that 3 cycles of ethanol (EtOH) resulted in an increase in GFAP immunoreactivity within the DG $(\mathbf{h})$ and CA1 (i), but not the CA2/3 (j). Moreover, no statically significant differences were observed between the water and sucrose (Suc) drinking group in any subregion of the hippocampus $(\mathbf{e}-\mathbf{g})$. c Scale bar, $10 \mu \mathrm{m}$. Each photomicrograph has traces outlining the hippocampal fissure. All data are presented as the mean \pm SEM. ${ }^{*} p<0.05$ compared to the water group.

Nondependent Binge-Induced Neuroimmune Responses in the Hippocampus like model, IL-1 $\beta$ and IL-10 may represent more vulnerable systems to binge drinking. For example, in a preclinical study of alcohol dependence increases in IL-4 and IL-6 in the central nervous system were observed following alcohol withdrawal [51]. The response observed herein after such acute exposure is troubling, but future studies should determine whether these changes in cytokine expression persist.

The functional implications of this cytokine dysregulation were not specifically examined in the current study, but our previous reports indicate that there is no neurodegeneration following the DID model, suggesting that this initial induction of cytokines is not necessarily engaged in the "classical" immune response associated with cell damage $[15,48,52]$. It is much more likely given the lack of neurodegeneration that these cytokines are involved with synaptic transmission and would lead to changes in behavior $[53,54]$. Various reports have shown that cytokine dysregulation in the hippocampus can cause memory impairments [55], including IL- $1 \beta[56,57]$ and IL-10 [58]. Given that lapses in memory are common following binge drinking $[59,60]$, it is perceivable that the dysregulation in cytokines observed herein play a role in these "gray-outs." Preclinical studies suggest that these lapses in memory occur even in the absence of neurodegeneration $[61,62]$. The cytokine-specific changes observed herein may mediate many of the complex behaviors caused by acute alcohol exposure and deserve further exploration.

Astrocyte activation has previously been shown to be induced by acute binge alcohol exposure in both in vitro and in vivo studies [63-65]. In fact, Mulligan et al. [66] found a cluster of astrocyte genes that were upregulated following just 1 day of binge-like alcohol consumption in a modified version of the DID paradigm. These results agree with those previous studies showing an increase in GFAP immunoreactivity induced by binge-like consumption levels. These studies only observed astrocyte activation after 3 cycles of DID using immunohistochemistry while others have reported activation after just a day of exposure $[63,66]$. These dissonant findings could be due to differences in the sensitivity of assays when examining gene changes in a microarray compared to proteins using IHC analysis [66]. In fact, our results showed binge-like alcohol consumption caused an increase in GFAP mRNA following just 1 week of DID, suggesting that qRT-PCR may be a more sensitive tool than IHC techniques in assessing ethanol's impact on astrocytes. Moreover, the Nixon lab has shown that higher BEC thresholds $(>300 \mathrm{mg} / \mathrm{dL})$ can 


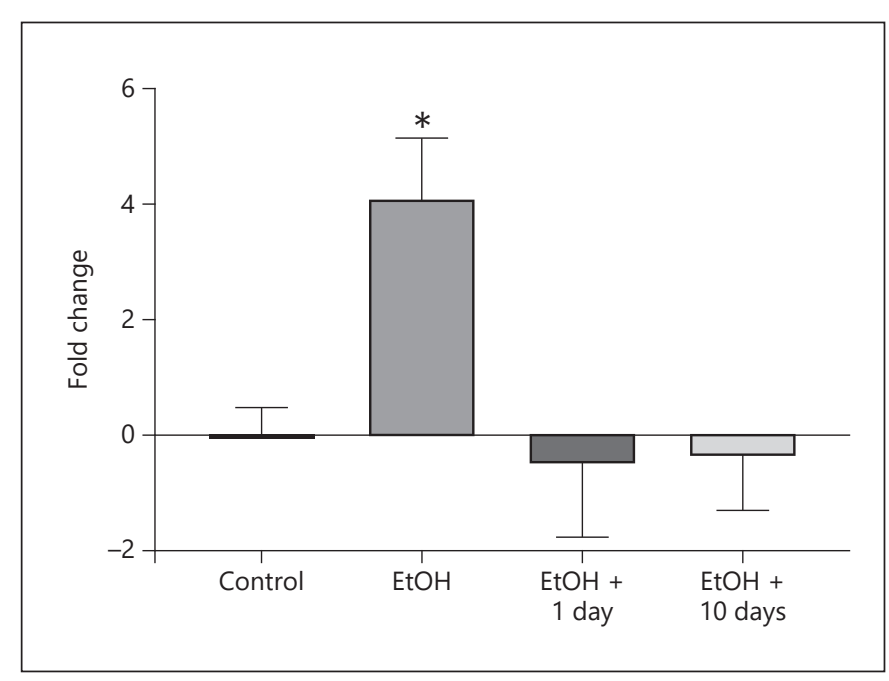

Fig. 6. One cycle of DID exposure caused increased GFAP mRNA expression in the hippocampus in the ethanol (EtOH) group compared with the water controls. This effect was only seen during alcohol intoxication and did not persist days after abstinence. All data are presented as the mean \pm SEM. ${ }^{*} p<0.05$ compared to the water group.

cause changes in GFAP protein revealed by immunohistochemistry after a single day of exposure [63]. It is important to denote that increased GFAP immunoreactivity could be indicative of an increased astrocyte number or morphological changes in astrocytes, but both are characteristic of astrogliosis [47]. Regardless of the temporal and alcohol exposure differences used in these models, the data converge to suggest that astrocytes within the hippocampus are particularly vulnerable to alcohol misuse. The role of astrocytes in alcohol consumption and related behaviors is an emerging field [67], and the current characterization of the astrocytic response after binge-like consumption is a step in determining the reciprocal relationship between astrocyte activation and alcohol abuse.

Together these findings indicate, even in the absence of neurodegeneration or dependence phenotypes, that binge alcohol consumption has a significant impact on neuroimmune functions in the hippocampus. One of the limitations of the current study is that it was not feasible to characterize other cytokines or the microglial response. Future studies should continue to examine cytokines and determine whether microglia are also dysregulated following binge-like consumption in the DID paradigm. A neuroimmune response in this model's more moderate, albeit problematic, level of binge-like alcohol consump- tion has serious implications for binge drinkers. Binge alcohol consumption often occurs in conjunction with other neuroimmune-modulating events, such as peripheral infections or traumatic brain injury [68-70]. These data suggest that more care should be taken to consider how alcohol misuse may confound neuroimmune function during such episodes, especially in light of the fact that binge drinking often goes unreported in clinical visits [71]. The social acceptability and prevalence of binge drinking makes considering how alcohol affects the neuroimmune system in nondependent individuals of critical importance. Binge-drinking effects on the neuroimmune system, as observed herein, have the potential to exacerbate neurodegeneration, but may also contribute to changes in behavioral comorbidities like memory deficits.

\section{Acknowledgments}

The authors thank Lauren E. Dorn, Dr. Scott Hemby, and Dr. Keir Fogarty of High Point University for their assistance. This work was supported by National Institutes of Health grants AA022048, GM000678, and AA011605. Support for these projects also came from the generous support of High Point University and the George T. Barthalmus Undergraduate Research Grant.

\section{Statement of Ethics}

The procedures used in this study were all approved by both High Point University and the University of North Carolina's Institutional Animal Care and Use Committees following the Guidelines for the Care and Use of Laboratory Animals.

\section{Disclosure Statement}

The authors declare no conflicts of interest.

\section{Author Contributions}

Alex Marshall, Todd Thiele, and Donald Lysle conceived and designed the experiments. Alex Marshall, Isabella Grifasi, and Scott McIntosh performed the experiments. Alex Marshall, Isabella Grifasi, and Rhiannon Thomas analyzed the data. Alex Marshall and Todd Thiele contributed reagents/materials/analysis tools. The report was written by all of the authors listed.
Grifasi/McIntosh/Thomas/Lysle/Thiele/ Marshall 


\section{References}

1 Grant BF, Saha TD, Ruan WJ, Goldstein RB, Chou SP, Jung J, et al. Epidemiology of DSM5 Drug Use Disorder: Results From the National Epidemiologic Survey on Alcohol and Related Conditions-III. JAMA Psychiatry. 2016 Jan;73(1):39-47.

2 Bloomfield K, Stockwell T, Gmel G, Rehn N. International comparisons of alcohol consumption. Alcohol Res Health. 2003;27(1): 95-109.

3 Rehm J. The risks associated with alcohol use and alcoholism. Alcohol Res Health. 2011; 34(2):135-43.

4 Rehm J, Mathers C, Popova S, Thavorncharoensap $\mathrm{M}$, Teerawattananon $\mathrm{Y}$, Patra J. Global burden of disease and injury and economic cost attributable to alcohol use and alcohol-use disorders. Lancet. 2009 Jun; 373(9682):2223-33.

5 Bouchery EE, Harwood HJ, Sacks JJ, Simon CJ, Brewer RD. Economic costs of excessive alcohol consumption in the U.S., 2006. Am J Prev Med. 2011 Nov;41(5):516-24.

6 NIAAA. NIAAA Council Approves Definition of Binge Drinking: National Institute on Alcohol Abuse and Alcoholism Newsletter. Bethesda (MD): National Institute of Health; 2004.

7 Gunzerath L, Hewitt BG, Li TK, Warren KR. Alcohol research: past, present, and future. Ann N Y Acad Sci. 2011 Jan;1216(1):1-23.

8 Centers for Disease Control and Prevention (CDC). Vital signs: binge drinking prevalence, frequency, and intensity among adults - United States, 2010. MMWR Morb Mortal Wkly Rep. 2012 Jan;61(1):14-9.

9 Koob GF. Alcoholism: allostasis and beyond. Alcohol Clin Exp Res. 2003 Feb;27(2):232-43.

10 Der-Avakian A, Markou A. The neurobiology of anhedonia and other reward-related deficits. Trends Neurosci. 2012 Jan;35(1):68-77.

11 Crews FT, Zou J, Qin L. Induction of innate immune genes in brain create the neurobiology of addiction. Brain Behav Immun. 2011 Jun;25 Suppl 1:S4-12.

12 Hutchinson MR, Watkins LR: Why is neuroimmunopharmacology crucial for the future of addiction research? Neuropharmacology. 2014;76(Pt B):218-227.

13 Marshall SA, Geil CR, Nixon K. Prior Binge Ethanol Exposure Potentiates the Microglial Response in a Model of Alcohol-Induced Neurodegeneration. Brain Sci. 2016 May;6(2):6.

14 Qin L, Crews FT. Focal thalamic degeneration from ethanol and thiamine deficiency is associated with neuroimmune gene induction, microglial activation, and lack of monocarboxylic acid transporters. Alcohol Clin Exp Res. 2014 Mar;38(3):657-71.

15 Marshall SA, Casachahua JD, Rinker JA, Blose AK, Lysle DT, Thiele TE. IL-1 receptor signaling in the basolateral amygdala modulates binge-like ethanol consumption in male C57BL/6J mice. Brain Behav Immun. 2016 Jan;51:258-67.
16 Bajo M, Herman MA, Varodayan FP, Oleata CS, Madamba SG, Harris RA, et al. Role of the IL-1 receptor antagonist in ethanol-induced regulation of GABAergic transmission in the central amygdala. Brain Behav Immun. 2015 Mar;45:189-97.

17 Bajo M, Varodayan FP, Madamba SG, Robert AJ, Casal LM, Oleata CS, et al. IL-1 interacts with ethanol effects on GABAergic transmission in the mouse central amygdala. Front Pharmacol. 2015 Mar;6:49.

18 Crews FT, Vetreno RP. Neuroimmune basis of alcoholic brain damage. Int Rev Neurobiol. 2014;118:315-57.

19 Marshall SA, McClain JA, Kelso ML, Hopkins DM, Pauly JR, Nixon K. Microglial activation is not equivalent to neuroinflammation in alcohol-induced neurodegeneration: the importance of microglia phenotype. Neurobiol Dis. 2013 Jun; 54:239-51.

20 Crews FT, Walter TJ, Coleman LG Jr, Vetreno RP. Toll-like receptor signaling and stages of addiction. Psychopharmacology (Berl). 2017 May;234(9-10):1483-98.

21 Zhao YN, Wang F, Fan YX, Ping GF, Yang JY, $\mathrm{Wu}$ CF. Activated microglia are implicated in cognitive deficits, neuronal death, and successful recovery following intermittent ethanol exposure. Behav Brain Res. 2013 Jan; 236(1):270-82

22 Sprow GM, Thiele TE. The neurobiology of binge-like ethanol drinking: evidence from rodent models. Physiol Behav. 2012 Jun; 106(3):325-31.

23 Esser MB, Hedden SL, Kanny D, Brewer RD, Gfroerer JC, Naimi TS. Prevalence of alcohol dependence among US adult drinkers, 20092011. Prev Chronic Dis. 2014 Nov;11:E206.

24 Epstein EE, Labouvie E, McCrady BS, Swingle J, Wern J. Development and validity of drinking pattern classification: binge, episodic, sporadic, and steady drinkers in treatment for alcohol problems. Addict Behav. 2004 Dec;29(9):1745-61.

25 Brett EI, Leavens EL, Miller MB, Lombardi N, Leffingwell TR. Normative perceptions of alcohol-related consequences among college students. Addict Behav. 2016 Jul;58:16-20.

26 Lac A, Donaldson CD. Alcohol attitudes, motives, norms, and personality traits longitudinally classify nondrinkers, moderate drinkers, and binge drinkers using discriminant function analysis. Addict Behav. 2016 Oct;61:91-8.

27 Williamson LL, Sholar PW, Mistry RS, Smith SH, Bilbo SD. Microglia and memory: modulation by early-life infection. J Neurosci. 2011 Oct;31(43):15511-21.

28 Perry VH, Holmes C. Microglial priming in neurodegenerative disease. Nat Rev Neurol. 2014 Apr;10(4):217-24.

29 Qin L, He J, Hanes RN, Pluzarev O, Hong JS, Crews FT. Increased systemic and brain cytokine production and neuroinflammation by endotoxin following ethanol treatment. J Neuroinflammation. 2008 Mar;5(1):10.
30 Qin L, Crews FT. Chronic ethanol increases systemic TLR3 agonist-induced neuroinflammation and neurodegeneration. J Neuroinflammation. 2012 Jun;9(1):130.

31 Thiele TE, Navarro M. "Drinking in the dark" (DID) procedures: a model of binge-like ethanol drinking in non-dependent mice. Alcohol. 2014 May;48(3):235-41.

32 Cox BR, Olney JJ, Lowery-Gionta EG, Sprow GM, Rinker JA, Navarro M, et al. Repeated cycles of binge-like ethanol (EtOH)-drinking in male C57BL/6J mice augments subsequent voluntary $\mathrm{EtOH}$ intake but not other dependence-like phenotypes. Alcohol Clin Exp Res. 2013 Oct;37(10): 1688-95.

33 Marshall SA, McKnight KH, Blose AK, Lysle DT, Thiele TE. Modulation of Binge-like Ethanol Consumption by IL-10 Signaling in the Basolateral Amygdala. J Neuroimmune Pharmacol. 2017 Jun;12(2):249-59.

34 Geil CR, Hayes DM, McClain JA, Liput DJ, Marshall SA, Chen KY, et al. Alcohol and adult hippocampal neurogenesis: promiscuous drug, wanton effects. Prog Neuropsychopharmacol Biol Psychiatry. 2014 Oct;54:10313.

35 Montesinos J, Alfonso-Loeches S, Guerri C. Impact of the Innate Immune Response in the Actions of Ethanol on the Central Nervous System. Alcohol Clin Exp Res. 2016 Nov; 40(11):2260-70.

36 Zahr NM, Mayer D, Rohlfing T, Hasak MP, Hsu O, Vinco S, et al. Brain injury and recovery following binge ethanol: evidence from in vivo magnetic resonance spectroscopy. Biol Psychiatry. 2010 May;67(9):846-54.

37 Zahr NM, Luong R, Sullivan EV, Pfefferbaum A. Measurement of serum, liver, and brain cytokine induction, thiamine levels, and hepatopathology in rats exposed to a 4-day alcohol binge protocol. Alcohol Clin Exp Res. 2010 Nov;34(11):1858-70.

38 Marshall SA, Rinker JA, Harrison LK, Fletcher CA, Herfel TM, Thiele TE. Assessment of the Effects of 6 Standard Rodent Diets on Binge-Like and Voluntary Ethanol Consumption in Male C57BL/6J Mice. Alcohol Clin Exp Res. 2015 Aug;39(8):1406-16.

39 Rhodes JS, Best K, Belknap JK, Finn DA, Crabbe JC. Evaluation of a simple model of ethanol drinking to intoxication in C57BL/6 mice. Physiol Behav. 2005 Jan;84(1):53-63.

40 Minami K, Wick MJ, Stern-Bach Y, DildyMayfield JE, Brozowski SJ, Gonzales EL, et al. Sites of volatile anesthetic action on kainate (Glutamate receptor 6) receptors. J Biol Chem. 1998 Apr;273(14):8248-55.

41 Kelso ML, Liput DJ, Eaves DW, Nixon K. Upregulated vimentin suggests new areas of neurodegeneration in a model of an alcohol use disorder. Neuroscience. 2011 Dec;197:38193.

42 Paxinos G, Franklin KB. The mouse brain in stereotaxic coordinates. 2nd ed. Amsterdam: Elsevier Academic Press; 2004.
Nondependent Binge-Induced Neuroimmune Responses in the Hippocampus
Neuroimmunomodulation 2019:26:19-32 
43 O'Connor JA, Muly EC, Arnold SE, Hemby SE. AMPA receptor subunit and splice variant expression in the DLPFC of schizophrenic subjects and rhesus monkeys chronically administered antipsychotic drugs. Schizophr Res. 2007 Feb;90(1-3):28-40.

44 O'Connor JA, Hemby SE. Elevated GRIA1 mRNA expression in Layer II/III and V pyramidal cells of the DLPFC in schizophrenia. Schizophr Res. 2007 Dec;97(1-3):277-88.

45 Kim HS, Lee G, John SW, Maeda N, Smithies O. Molecular phenotyping for analyzing subtle genetic effects in mice: application to an angiotensinogen gene titration. Proc Natl Acad Sci USA. 2002 Apr;99(7):4602-7.

46 Crabbe JC, Wahlsten D, Dudek BC. Genetics of mouse behavior: interactions with laboratory environment. Science. 1999 Jun; 284(5420):1670-2.

47 Yang Z, Wang KK. Glial fibrillary acidic protein: from intermediate filament assembly and gliosis to neurobiomarker. Trends Neurosci. 2015 Jun;38(6):364-74.

48 Sprow GM, Rinker JA, Lowery-Gointa EG, Sparrow AM, Navarro M, Thiele TE. Lateral hypothalamic melanocortin receptor signaling modulates binge-like ethanol drinking in C57BL/6J mice. Addict Biol. 2016 Jul;21(4): 835-46.

49 Kane CJ, Phelan KD, Douglas JC, Wagoner G, Johnson JW, Xu J, et al. Effects of ethanol on immune response in the brain: region-specific changes in adolescent versus adult mice. Alcohol Clin Exp Res. 2014 Feb;38(2):384-91.

50 Drew PD, Johnson JW, Douglas JC, Phelan KD, Kane CJ. Pioglitazone blocks ethanol induction of microglial activation and immune responses in the hippocampus, cerebellum, and cerebral cortex in a mouse model of fetal alcohol spectrum disorders. Alcohol Clin Exp Res. 2015 Mar;39(3):445-54.

51 Walter TJ, Crews FT. Microglial depletion alters the brain neuroimmune response to acute binge ethanol withdrawal. J Neuroinflammation. 2017 Apr;14(1):86.

52 Mayfield J, Ferguson L, Harris RA. Neuroimmune signaling: a key component of alcohol abuse. Curr Opin Neurobiol. 2013 Aug;23(4): $513-20$.
53 Galic MA, Riazi K, Pittman QJ. Cytokines and brain excitability. Front Neuroendocrinol. 2012 Jan;33(1):116-25.

54 Kelley KW, McCusker RH. Getting nervous about immunity. Semin Immunol. 2014 Oct; 26(5):389-93.

55 Vitkovic L, Bockaert J, Jacque C. "Inflammatory" cytokines: neuromodulators in normal brain? J Neurochem. 2000 Feb;74(2):457-71.

56 Song C, Zhang Y, Dong Y. Acute and subacute IL- $1 \beta$ administrations differentially modulate neuroimmune and neurotrophic systems: possible implications for neuroprotection and neurodegeneration. J Neuroinflammation. 2013 May;10(1):59.

57 Gonzalez P, Machado I, Vilcaes A, Caruso C, Roth GA, Schiöth H, et al. Molecular mechanisms involved in interleukin 1-beta (IL-1 $\beta$ )induced memory impairment. Modulation by alpha-melanocyte-stimulating hormone ( $a$ MSH). Brain Behav Immun. 2013 Nov;34: 141-50.

58 Richwine AF, Sparkman NL, Dilger RN, Buchanan JB, Johnson RW. Cognitive deficits in interleukin-10-deficient mice after peripheral injection of lipopolysaccharide. Brain Behav Immun. 2009 Aug;23(6):794-802.

59 White AM. What happened? Alcohol, memory blackouts, and the brain. Alcohol Res Health. 2003;27(2):186-96.

60 Perry PJ, Argo TR, Barnett MJ, Liesveld JL, Liskow B, Hernan JM, et al. The association of alcohol-induced blackouts and grayouts to blood alcohol concentrations. J Forensic Sci. 2006 Jul;51(4):896-9.

61 Silvestre de Ferron B, Bennouar KE, Kervern M, Alaux-Cantin S, Robert A, Rabiant K, et al. Two Binges of Ethanol a Day Keep the Memory Away in Adolescent Rats: Key Role for GLUN2B Subunit. Int J Neuropsychopharmacol. 2015 Aug;19(1):19.
62 Hunt PS, Barnet RC. Adolescent and adult rats differ in the amnesic effects of acute ethanol in two hippocampus-dependent tasks: trace and contextual fear conditioning. Behav Brain Res. 2016 Feb;298(Pt A):78-87.

63 Hayes DM, Deeny MA, Shaner CA, Nixon K. Determining the threshold for alcohol-induced brain damage: new evidence with gliosis markers. Alcohol Clin Exp Res. 2013 Mar; 37(3):425-34.

64 Lacagnina MJ, Rivera PD, Bilbo SD. Glial and neuroimmune mechanisms as critical modulators of drug use and abuse. Neuropsychopharmacology. 2017 Jan;42(1):156-177.

65 Pignataro L, Varodayan FP, Tannenholz LE, Protiva P, Harrison NL. Brief alcohol exposure alters transcription in astrocytes via the heat shock pathway. Brain Behav. 2013 Mar; 3(2):114-33.

66 Mulligan MK, Rhodes JS, Crabbe JC, Mayfield RD, Harris RA, Ponomarev I. Molecular profiles of drinking alcohol to intoxication in C57BL/6J mice. Alcohol Clin Exp Res. 2011 Apr;35(4):659-70.

67 Adermark L, Bowers MS. Disentangling the Role of Astrocytes in Alcohol Use Disorder. Alcohol Clin Exp Res. 2016 Sep;40(9):180216.

68 Niciu MJ, Henter ID, Sanacora G, Zarate CA Jr. Glial abnormalities in substance use disorders and depression: does shared glutamatergic dysfunction contribute to comorbidity? World J Biol Psychiatry. 2014 Jan;15(1):2-16.

69 Miguel-Hidalgo JJ, Waltzer R, Whittom AA, Austin MC, Rajkowska G, Stockmeier CA. Glial and glutamatergic markers in depression, alcoholism, and their comorbidity [Corrected Proof]. J Affect Disord. 2010 Dec; 127(1-3):230-40

70 Tyas SL. Alcohol use and the risk of developing Alzheimer's disease. Alcohol Res Health. 2001;25(4):299-306.

71 McKnight-Eily LR, Okoro CA, Mejia R, Denny $\mathrm{CH}$, Higgins-Biddle J, Hungerford D, et al. Screening for Excessive Alcohol Use and Brief Counseling of Adults - 17 States and the District of Columbia, 2014. MMWR Morb Mortal Wkly Rep. 2017 Mar;66(12):313-9. 